\title{
Triglyceride is independently correlated with insulin resistance and islet beta cell function: a study in population with different glucose and lipid metabolism states
}

Minglei Ma', Haibin Liu², Jie Yu', Shuli He ${ }^{3}$, Pingping Li ${ }^{4,5}$, Chunxiao Ma ${ }^{4,5}$, Huabing Zhang ${ }^{1}$, Lingling Xu', Fan Ping ${ }^{1}$, Wei Li ${ }^{1}$, Qi Sun ${ }^{1}$ and Yuxiu Li ${ }^{1 *}$

\begin{abstract}
Background: Previous studies on the effects of lipotoxicity and oxidative stress on islet beta cell function mainly focused on patients with diabetes, whereas studies on normal glucose tolerance (NGT) are few. The aim of this study was to explore the relationships among triglyceride (TG), high-density lipoprotein cholesterol (HDL-c), lowdensity lipoprotein cholesterol (LDL-c), oxidative stress indicators, insulin resistance, and beta cell function in populations with different glucose and lipid metabolism states.

Methods: A total of 517 individuals were recruited from a rural community in Beijing, China. Glucose metabolism status was defined according to the results of a 75-g oral glucose tolerance test (OGTT). Dyslipidemia was defined as abnormal TG, HDL-c, or LDL-c levels. The population was divided into four groups: individuals with normal glucose and lipid levels (group A, $n=62$ ); those with dyslipidemia alone (group $B, n=82$ ); those with dysglycemia alone (group $C, n=121$ ); and those with dysglycemia and dyslipidemia (group $D, n=247$ ). Oxidative stress indicators, including superoxide dismutase (SOD), glutathione reductase (GR) and 8-hydroxydeoxyguanosine (8$\mathrm{OHdG}$ ), were measured. Homeostasis model assessment of insulin resistance (HOMA-IR) and glucose disposition index $\left(\mathrm{Dl}_{30}, \mathrm{Dl}_{120}\right)$ were calculated to assess insulin resistance and islet beta cell function, respectively. Stratified multiple linear regression analysis was used to explore relationships between $T G, H D L-C$, LDL-C, oxidative stress indicators, and insulin resistance (natural log transformation of HOMA-IR, LnHOMA-IR) and beta cell function (natural log transformation of $\left.\mathrm{DI}_{30}, \mathrm{Ln} \mathrm{DI}_{30}\right)$.

(Continued on next page)
\end{abstract}

\footnotetext{
* Correspondence: liyuxiu@medmail.com.cn

'Department of Endocrinology, Key Laboratory of Endocrinology, Ministry of Health, Peking Union Medical College Hospital, Beijing 100730, China

Full list of author information is available at the end of the article
}

(c) The Author(s). 2020 Open Access This article is licensed under a Creative Commons Attribution 4.0 International License, which permits use, sharing, adaptation, distribution and reproduction in any medium or format, as long as you give appropriate credit to the original author(s) and the source, provide a link to the Creative Commons licence, and indicate if changes were made. The images or other third party material in this article are included in the article's Creative Commons licence, unless indicated otherwise in a credit line to the material. If material is not included in the article's Creative Commons licence and your intended use is not permitted by statutory regulation or exceeds the permitted use, you will need to obtain permission directly from the copyright holder. To view a copy of this licence, visit http://creativecommons.org/licenses/by/4.0/ The Creative Commons Public Domain Dedication waiver (http://creativecommons.org/publicdomain/zero/1.0/) applies to the data made available in this article, unless otherwise stated in a credit line to the data. 
(Continued from previous page)

Results: Compared with the control group, populations with dyslipidemia and/or dysglycemia showed significantly increased insulin resistance. Dyslipidemia aggravated insulin resistance and beta cell dysfunction in individuals with dysglycemia. Stratified regression analysis showed that TG positively correlated with LnHOMA-IR in individuals with normal glucose levels (beta $=0.321,0.327, P=0.011,0.003$ in groups $A$ and $B$, respectively) and negatively correlated with $\mathrm{LnDl}_{30}$ in participants with dyslipidemia (beta $=-0.225,-0.122, P=0.035,0.048$ in groups $\mathrm{B}$ and $\mathrm{D}$, respectively). Reduced serum SOD levels in individuals with dysglycemia plus dyslipidemia were observed, and a negative association between TG and SOD levels was found ( $r=-0.461, P<0.001$ ).

Conclusion: TG correlated with both insulin resistance and beta cell function in individuals with dyslipidemia alone. SOD negatively correlated with TG, indicating a close relationship between oxidative stress and glucose-lipid metabolism. Due to the adverse effect of hypertriglyceridemia on insulin sensitivity and islet beta cell function, more attention should be paid to the detection and management of hypertriglyceridemia.

Keywords: Glucose, Lipid, Diabetes, Triglyceride, Superoxide dismutase, Insulin resistance, Beta cell function, Oxidative stress

\section{Background}

As living conditions improve, lifestyle-related metabolic diseases, including diabetes (DM), obesity, dyslipidemia, and hyperuricemia, are becoming increasingly prevalent worldwide. Dyslipidemia is very common in patients with type 2 diabetes (T2DM), with a prevalence of $72-$ $85 \%$ in this population [1]. According to previous studies, elevated triglyceride (TG) and decreased highdensity lipoprotein cholesterol (HDL-c) are characteristic features of diabetic dyslipidemia [1, 2]. Patients with diabetes have an increased risk of cardiovascular disease (CVD), and low-density lipoprotein cholesterol (LDL-c) is an independent risk factor for CVD. Currently, lipidlowering therapy for patients with diabetes primarily focuses on the reduction in LDL-c through the use of statins, while treatment aimed at lowering TG levels is relatively inadequate $[3,4]$.

Insulin resistance and impaired islet beta cell function are two major defects that contribute to the occurrence of T2DM. These defects may also contribute to the development of impaired fasting glucose (IFG) and impaired glucose tolerance (IGT), conditions that occur in the early stages of diabetes $[5,6]$. As one component of metabolic syndrome, insulin resistance is closely related to obesity and dyslipidemia. Studies have shown that the TG/HDL-c ratio can be used to predict insulin resistance in Caucasian and Chinese Han populations [7-9], reflecting the close relationship among TG, HDL-c, and insulin resistance. Lipotoxicity can not only induce insulin resistance but also impair beta cell function. Both chronic hyperglycemia (glucotoxicity) and chronic hyperlipidemia (lipotoxicity) can impair islet beta cell function [10]. It has also been suggested that lipotoxicity damages islet beta cell function only under high-glucose conditions (glucolipotoxicity) [11-13]. Previous studies of lipotoxicity have primarily focused on diabetic mouse models or on patients with diabetes [14-16], whereas studies of individuals with normal glucose tolerance (NGT) are few [17].

Previous studies have shown that oxidative stress are involved in the pathogenesis of insulin resistance and islet beta cell dysfunction as well as in the development of diabetes [18-22]. Oxidative stress is the result of an imbalance between the formation and the enzymatic or nonenzymatic clearance of reactive oxygen species (ROS). Due to the low levels of antioxidant defense enzymes present in islets, beta cells are extremely susceptible to oxidative stress damage [23]. Very few studies have focused on the relationships among serum lipid levels, oxidative stress indicators, insulin resistance, and beta cell function in populations with different states of glucose and lipid metabolism, especially in individuals with hyperglycemia alone, dyslipidemia alone, or normal glucose and lipid metabolism.

It is hypothesized that TG, HDL-c, LDL-c and ROS might contribute differently to insulin resistance and islet beta cell dysfunction in people with different glucose and lipid levels. To address this issue, the relationship between serum lipid levels, oxidative stress indicators, insulin resistance, and islet beta cell function was explored in a previously healthy population residing in a rural community in Beijing, China.

\section{Methods \\ Study population}

This is a community-based cross-sectional study. The participants were recruited between March 2014 and January 2015 from a type 2 diabetes project in a suburb of Beijing, China. The study recruited participants from 599 participants who underwent a 75-g oral glucose tolerance test (OGTT). The exclusion criteria were as follows: 1) patients previously diagnosed with diabetes or who were taking hypoglycemic drugs $(n=57) ; 2)$ patients previously treated with steroid drugs or lipid-lowering 
drugs $(n=25,22$ of whom were also taking hypoglycemic drugs); and 3) patients with severe cardiovascular, hepatic, or kidney disease $(n=7)$. After excluding patients who did not meet the requirements $(n=67)$ and those for whom the data were incomplete $(n=15)$, 517 patients were included in the analysis (Fig. 1). The study protocol was approved by the Ethics Committee of Peking Union Medical College Hospital (Approval Number: ZS-1274), and all patients signed an informed consent form.

\section{Demographic data}

Waist circumference (WC) was measured midway between the iliac crest and the costal margin. Height and weight were measured in patients without shoes wearing thin clothing and used to calculate the patient's body mass index (BMI) according to the formula BMI = weight $(\mathrm{kg}) /$ height $(\mathrm{m})^{2}$. According to the 2004 World Health Organization's recommendation for Asian people, being overweight was defined as BMI $\geq 23 \mathrm{~kg} / \mathrm{m}^{2}$ and obesity as BMI $\geq 27.5 \mathrm{~kg} / \mathrm{m}^{2}$ [24]. Blood pressure at rest in the sitting position was measured twice with a standard mercury sphygmomanometer, and the average value was used.

\section{Biochemical test}

Venous blood was collected through the elbow vein from participants who had fasted for at least $10 \mathrm{~h}$ (overnight fasting). The serum lipid profile, including total cholesterol (TC), TG, HDL-c, and LDL-c, was measured using a Beckman CX4 automatic biochemical analyzer (interassay coefficient of variation $<3 \%$, testing performed with help from the laboratory staff at Peking Union Medical College Hospital). Glycosylated hemoglobin (HbA1c) was detected using the National Glycohemoglobin Standardization Program (NGSP) certification method. All patients underwent a 2-h OGTT in which they ingested $75 \mathrm{~g}$ of glucose powder. Venous blood was collected at 0, 30, 60, and $120 \mathrm{~min}$ and used to measure plasma glucose (glucose oxidase method), insulin (chemiluminescent enzyme immunoassay), and $\mathrm{C}$ peptide (C-P, chemiluminescent enzyme immunoassay) levels. The trapezoidal method was used to calculate the areas under the curves of glucose $\left(\mathrm{AUC}_{\mathrm{Glu}}\right)$, insulin $\left(\mathrm{AUC}_{\mathrm{INS}}\right)$ and $\mathrm{C}$ peptide $\left(\mathrm{AUC}_{\mathrm{C}-\mathrm{P}}\right)$ from the OGTT.

\section{Oxidative stress indicators}

Serum superoxide dismutase (SOD), glutathione reductase (GR), 8-hydroxydeoxyguanosine (8-OHdG) levels were determined using enzyme-linked immunosorbent assay (ELISA) kits (Cloud-Clone Corp, Houston, TX, USA); these measurements were conducted with help from Beijing North Institute of Biological Technology.

\section{Assessment of insulin resistance and beta cell function}

Assessment of insulin resistance and insulin sensitivity was performed using the following models. (1) Homeostasis model assessment of insulin resistance (HOMAIR): HOMA-IR = fasting blood glucose $(\mathrm{mmol} / \mathrm{L}) \times$ fasting insulin $(\mu \mathrm{IU} / \mathrm{mL}) / 22.5$ [25]. HOMA-IR is determined from results on fasting indices and is mainly used to estimate hepatic insulin sensitivity. (2) Matsuda insulin sensitivity index $\left(\mathrm{ISI}_{\mathrm{M}}\right): \mathrm{ISI}_{\mathrm{M}}=10^{4} /[$ (fasting blood glucose $\times$ fasting insulin) $\times$ (average blood glucose $\times$ average insulin)] ${ }^{0.5}[26]$. ISI $_{M}$ can be used as a measure of whole-body insulin sensitivity. (3) Quantitative insulin sensitivity check index (QUICKI): QUICKI $=1 /[\log$ insulin $(\mu \mathrm{IU} / \mathrm{mL})+\log$ glucose $(\mathrm{mg} / \mathrm{dL})]$ [27].

Evaluation of islet beta cell secretory function was performed as follows. (1) The insulinogenic index (IGI) was assessed for early-phase insulin secretion assessment $\left(\mathrm{IGI}_{30}=\Delta \mathrm{INS}_{0-30} / \Delta \mathrm{Glu}_{0-30}[28]\right)$ and for late-phase

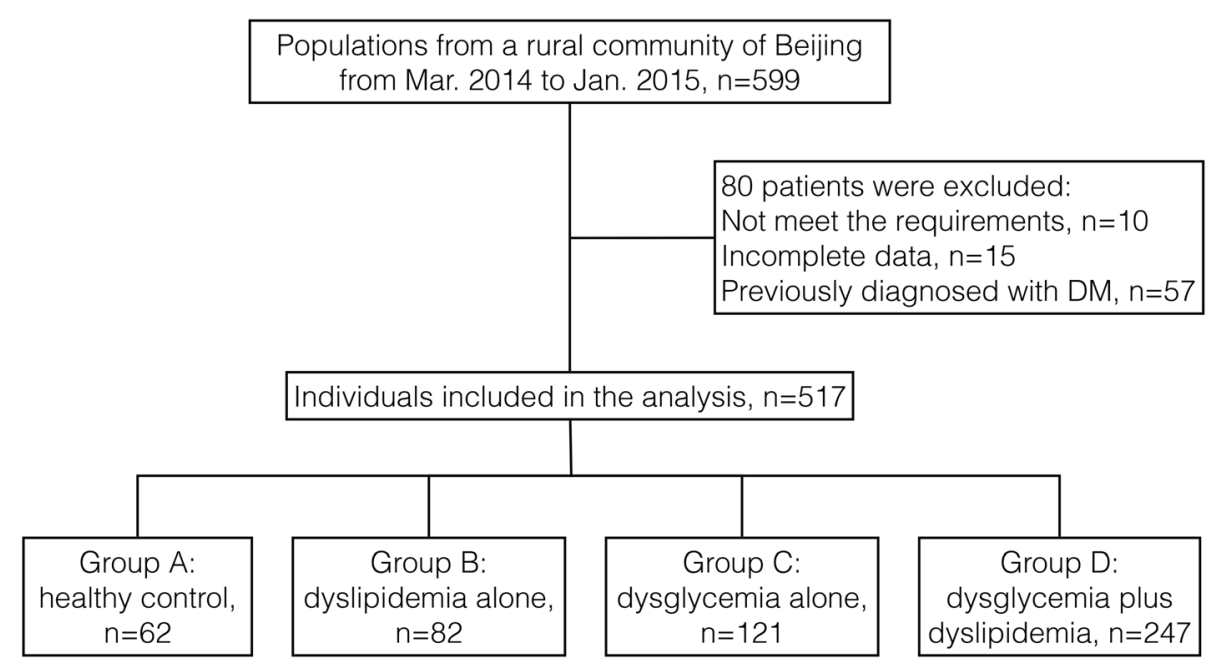

Fig. 1 Flow chart of the study 
insulin secretion $\left(\mathrm{IGI}_{120}=\Delta \mathrm{INS}_{0-120} / \Delta \mathrm{Glu}_{0-120}\right)$. (2) The disposition index (DI), a comprehensive evaluation of insulin secretion and insulin resistance, was measured as 1 ) beta cell function adjusted for insulin sensitivity: $\mathrm{DI}=$ HOMA- $\beta / H O M A-I R$ [29]; 2) early-phase glucose DI: $\mathrm{DI}_{30}=\Delta \mathrm{INS}_{0-30} / \Delta \mathrm{Glu}_{0-30}{ }^{*} \mathrm{ISI}_{\mathrm{M}}$; and 3) late-phase glucose DI: $\mathrm{DI}_{120}=\Delta \mathrm{INS}_{0-120} / \Delta \mathrm{Glu}_{0-120}{ }^{*} \mathrm{ISI}_{\mathrm{M}}[30]$.

\section{Definition of glucose tolerance}

According to the diagnostic criteria set forth by the 1999 World Health Organization (WHO), all patients were stratified for glucose tolerance; those with fasting plasma glucose $(\mathrm{FPG}) \geq 7.0 \mathrm{mmol} / \mathrm{L}$ or 2 -h postprandial plasma glucose (PPG) $\geq 11.0 \mathrm{mmol} / \mathrm{L}$ were defined as having $\mathrm{DM}$, those with $\mathrm{FPG} \geq 6.1 \mathrm{mmol} / \mathrm{L}$ but $<7.0 \mathrm{mmol} / \mathrm{L}$ or 2-h PPG $\geq 7.8 \mathrm{mmol} / \mathrm{L}$ but $<11.0 \mathrm{mmol} / \mathrm{L}$ were defined as having prediabetes (pre-DM), and those with FPG < $6.1 \mathrm{mmol} / \mathrm{L}$ and $2-\mathrm{h}$ PPG $<7.8 \mathrm{mmol} / \mathrm{L}$ were defined as having NGT. Of the study participants, 118 (22.8\%) were newly diagnosed with DM, 255 (49.3\%) were diagnosed as having pre-DM, and $144(27.9 \%)$ were diagnosed as having NGT.

\section{Definition of dyslipidemia}

Dyslipidemia associated with T2DM is characterized by high TG and low HDL-c levels. In addition, T2DM is a high-risk factor for CVDs, and low LDL-c levels are closely related to the occurrence of CVDs. Therefore, the definition of dyslipidemia in this study is primarily based on abnormalities in TG and/or HDL-c or LDL-c levels. The definition of dyslipidemia used in this study was based on the definitions of abnormal TG and HDLc levels in metabolic syndrome provided by the $2005 \mathrm{Na}-$ tional Cholesterol Education Program (NCEP) and the 2006 International Diabetes Federation (IDF) and was indicated by a TG level $\geq 1.7 \mathrm{mmol} / \mathrm{L}$, an HDL-c level < $1.03 \mathrm{mmol} / \mathrm{L}$ (male) or $<1.3 \mathrm{mmol} / \mathrm{L}$ (female), or an LDL-c level $\geq 3.37 \mathrm{mmol} / \mathrm{L}$ (based on the upper limit of the laboratory reference range). Among the participants, 192 (37.5\%) had increased TG levels $\geq 1.7 \mathrm{mmol} / \mathrm{L}, 209$ (40.8\%) had decreased HDL-c levels $<1.0 \mathrm{mmol} / \mathrm{L}$ (male) or $<1.3 \mathrm{mmol} / \mathrm{L}$ (female), and 107 (20.9\%) had increased LDL-c levels $\geq 3.37 \mathrm{mmol} / \mathrm{L}$. Any single abnormality in TG, HDL-c, and LDL-c levels was defined as dyslipidemia. Among the participants, 329 (63.6\%) had dyslipidemia, and 188 (36.3\%) had normal serum lipids.

\section{Group of participants}

Because the study did not include patients who had previously been diagnosed with $\mathrm{DM}$, individuals with newly diagnosed DM and pre-DM were grouped together in the dysglycemia group. Further grouping was based on glucose tolerance and serum lipid levels. Therefore, the population was divided into the following four groups (due to partial data loss, four patients were not included in the group analysis): group A, healthy controls (normal glucose and lipid levels, $n=62$ ); group $B$, individuals with dyslipidemia alone (dyslipidemia and NGT, $n=82$ ); group $\mathrm{C}$, individuals with dysglycemia alone (pre-DM or newly diagnosed DM and normal serum lipids, $n=121$ ); and group D, individuals with both dysglycemia and dyslipidemia (pre-DM or newly diagnosed DM with dyslipidemia, $n=247$ ) (Fig. 1).

\section{Statistical methods}

Continuous data are expressed as the mean $\pm \mathrm{SD}$ or as the median (Q1, Q3), and categorical variables are expressed as counts/percentiles (\%). Normality was assessed for all continuous variables, and nonnormally distributed data were transformed using the natural log (Ln) value where relevant. Differences in normally distributed data among groups were assessed by one-way analysis of variance (ANOVA) with post hoc Bonferroni correction for multiple comparisons. Differences in nonnormally distributed data among groups were assessed using the nonparametric test, and $P$ values comparing two groups were corrected by the Bonferroni method. Spearman correlation analysis was used to assess the association of different indicators with insulin resistance (HOMA-IR) and insulin secretion $\left(\mathrm{DI}_{30}\right)$ in the overall population. In the multivariate linear regression analysis, the population was grouped according to states of glucose and lipid metabolism, and LnHOMA-IR and $\mathrm{LnDI}_{30}$ were used as dependent variables to evaluate the correlations among lipid profiles, oxidative stress indicators, insulin resistance, and beta cell function. Statistically significant variables $(P<0.2)$ from the univariate linear regression analyses were included in the multiple linear regression analysis. All statistical analyses were performed using IBM SPSS Statistics 23.0 (IBM Corp., Armonk, NY, USA). A P value $<0.05$ was considered significant.

\section{Results \\ Basic characteristics of the groups}

The average age of the study population was $52.63 \pm$ 11.08 years; individuals with dysglycemia (groups $\mathrm{C}$ and D) were on average older than those with NGT (groups $\mathrm{A}$ and $\mathrm{B}$ ). Most individuals in groups $\mathrm{B}, \mathrm{C}$, and $\mathrm{D}$ were overweight or obese; the average BMI of the individuals in these groups was higher than that of group A. Among the individuals with normal serum lipid levels, those with dysglycemia (group C) showed a significant increase in LDL-c levels compared with those with NGT (group A). In participants with dyslipidemia, dysglycemic individuals (group D) had higher TG, TC, and LDL-c levels than participants with NGT (group B). The SOD level of group D was significantly reduced compared with that of group C (Table 1). 
Table 1 Basic characteristics of the general population and of participants with different levels of glucose and lipid metabolism

\begin{tabular}{|c|c|c|c|c|c|c|}
\hline & & Group A & Group B & Group C & Group D & \\
\hline & Total & NGT \& NL & NGT \& DL & IGT or DM \& NL & IGT or DM \& DL & \\
\hline & $N=517$ & $N=62(12.1 \%)$ & $N=82(16.0 \%)$ & $N=121(23.6 \%)$ & $N=247(48.2 \%)$ & $P$ \\
\hline Female (\%) & 334 (65.2\%) & $43(69.4 \%)$ & $56(68.3 \%)$ & $69(57.0 \%)$ & $166(67.2 \%)$ & 0.185 \\
\hline Age (years) & $52.63 \pm 11.08$ & $47.37 \pm 12.54$ & $48.35 \pm 12.33$ & $54.47 \pm 10.52 \dagger \neq$ & $54.45 \pm 9.70 \dagger \neq$ & $<0.001$ \\
\hline $\mathrm{BMI}\left(\mathrm{kg} / \mathrm{m}^{2}\right)$ & $26.07 \pm 3.78$ & $23.46 \pm 3.06$ & $25.57 \pm 2.97 \dagger$ & $25.48 \pm 3.76+$ & $27.18 \pm 3.80 \dagger \neq \S$ & $<0.001$ \\
\hline WC $(\mathrm{cm})$ & $87.22 \pm 9.83$ & $81.28 \pm 9.51$ & $85.11 \pm 8.91$ & $86.33 \pm 9.52 \dagger$ & $89.86 \pm 9.50 \dagger \neq \S$ & $<0.001$ \\
\hline Obesity & $170(33.1 \%)$ & $6(9.7 \%)$ & $20(24.4 \%)$ & $35(29.2 \%)$ & $108(43.9 \%)$ & $<0.001$ \\
\hline Overweight or obesity & 415 (80.7\%) & $32(51.6 \%)$ & $66(80.5 \%)$ & 95 (79.2\%) & $219(89 \%)$ & $<0.001$ \\
\hline $\mathrm{SBP}(\mathrm{mmHg})$ & $127.71 \pm 18.84$ & $121.95 \pm 16.55$ & $123.44 \pm 16.01$ & $126.47 \pm 20.15$ & $131.17 \pm 18.97 \dagger \neq$ & $<0.001$ \\
\hline $\mathrm{DBP}(\mathrm{mmHg})$ & $76.15 \pm 10.12$ & $75.15 \pm 10.28$ & $76.85 \pm 9.75$ & $75.39 \pm 9.29$ & $76.54 \pm 10.60$ & 0.568 \\
\hline $\mathrm{HbA} 1 \mathrm{c}(\%)$ & $5.6(5.3,6.0)$ & $5.2(5.0,5.4)$ & $5.3(5.1,5.6)$ & $5.6(5.3,5.9) \dagger \neq$ & $5.9(5.5,6.3) \dagger \neq \S$ & $<0.001$ \\
\hline FPG $(\mathrm{mmol} / \mathrm{L})$ & $5.92(5.46,6.61)$ & $5.27(5.01,5.39)$ & $5.30(5.10,5.48)$ & $6.07(5.81,6.61) \dagger \neq$ & $6.35(5.86,7.21)+\neq$ & $<0.001$ \\
\hline $\mathrm{TG}(\mathrm{mmol} / \mathrm{L})$ & $1.40(0.98,2.06)$ & $0.91(0.68,1.20)$ & $1.53(0.99,2.13) \dagger$ & $1.01(0.8,1.30) \neq$ & $1.89(1.39 .2 .58) \dagger \neq \S$ & $<0.001$ \\
\hline $\mathrm{HDL}-\mathrm{c}(\mathrm{mmol} / \mathrm{L})$ & $1.27(1.08,1.47)$ & $1.47(1.36,1.61)$ & $1.13(1.01 .1 .26)+$ & $1.45(1.32,1.63) \neq$ & $1.17(1.03,1.32)+\S$ & $<0.001$ \\
\hline $\mathrm{TG} / \mathrm{HDL}-\mathrm{C}$ & $1.14(0.71,1.83)$ & $0.64(0.42,0.83)$ & $1.32(0.83,2.08) \dagger$ & $0.70(0.52,0.93) \neq$ & $1.62(1.18,2.52) \dagger \neq \S$ & $<0.001$ \\
\hline $\mathrm{TC}(\mathrm{mmol} / \mathrm{L})$ & $5.49 \pm 1.03$ & $4.99 \pm 0.61$ & $5.35 \pm 1.18$ & $5.32 \pm 0.81$ & $5.73 \pm 1.09 \dagger \neq \S$ & $<0.001$ \\
\hline LDL-c (mmol/L) & $2.84 \pm 0.71$ & $2.31 \pm 0.46$ & $2.85 \pm 0.82 \dagger$ & $2.61 \pm 0.51 \dagger$ & $3.08 \pm 0.71 \dagger \neq \S$ & $<0.001$ \\
\hline $\mathrm{UA}(\mu \mathrm{mol} / \mathrm{L})$ & $291.61 \pm 83.38$ & $266.09 \pm 78.51$ & $283.52 \pm 71.90$ & $275.89 \pm 74.97$ & $308.39 \pm 88.77 \dagger$ & $<0.001$ \\
\hline 8-OHdG (pg/ml) & $37.76(19.82,58.66)$ & $38.65(18.72,58.49)$ & $36.10(17.86,62.76)$ & $41.66(25.02,55.35)$ & $36.96(19.66,59.80)$ & 0.9 \\
\hline SOD level (U/ml) & $58.95 \pm 20.97$ & $60.60 \pm 15.73$ & $59.95 \pm 18.01$ & $64.31 \pm 17.27$ & $55.71 \pm 23.92 \S$ & 0.003 \\
\hline $\mathrm{GR}(\mathrm{U} / \mathrm{L})$ & $7.19 \pm 3.25$ & $7.34 \pm 3.33$ & $6.59 \pm 3.12$ & $7.43 \pm 3.19$ & $7.25 \pm 3.30$ & 0.304 \\
\hline
\end{tabular}

$B M I$ Body mass index, WC Waist circumference, SBP Systolic blood pressure, DBP Diastolic blood pressure, HbA1c Glycosylated hemoglobin, FPG Fasting blood glucose, TG Triglyceride, HDL-c High-density lipoprotein cholesterol, TC total cholesterol, LDL-c Low-density lipoprotein cholesterol, UA Uric acid, 8-OHdG 8hydroxydeoxyguanosine, SOD Superoxide dismutase, GR Glutathione reductase. t: $P<0.05$ compared with group $A$

\#: $P<0.05$ compared with group $B$

$\S: P<0.05$ compared with group $C$

\section{Comparison of glucose and insulin levels during the OGTT} Compared with the individuals in group $\mathrm{A}$, the insulin levels of those in group B during fasting and at 30, 60, and $120 \mathrm{~min}$ of the OGTT were significantly increased, but the blood glucose levels of these two groups did not differ significantly at any of the time points. Group $\mathrm{C}$ showed a significant increase in blood glucose at various time points of the OGTT compared with group A, but there were no significant differences in the insulin levels of these two groups at 0,30 , or $60 \mathrm{~min}$. The insulin level at $120 \mathrm{~min}$ was significantly higher than that in the control group. The $\mathrm{AUC}_{\mathrm{Glu}}$ of the individuals in groups $\mathrm{C}$ and $\mathrm{D}$ was higher than that of those in groups $\mathrm{A}$ and $\mathrm{B}$. The $\mathrm{AUC}_{\mathrm{INS}}$ was higher in patients with dyslipidemia than in individuals with normal lipid levels both in patients with NGT and in those with pre-DM/DM (group B vs. group A and group D vs. group C) (Fig. 2, Suppl. Table 1).

\section{Comparison of insulin resistance and islet beta cell function among groups}

Compared with the normal control group (group A), groups $\mathrm{B}, \mathrm{C}$, and $\mathrm{D}$ all showed significantly higher
HOMA-IR and significantly lower insulin sensitivity as indicated by QUICKI and $\mathrm{ISI}_{\mathrm{M}}$. Compared with groups $\mathrm{B}$ and $\mathrm{C}$, group $\mathrm{D}$ had more severe insulin resistance (HOMA-IR) and poorer insulin sensitivity (QUICKI and $\mathrm{ISI}_{\mathrm{M}}$ ). However, there were no significant differences in HOMA-IR, QUICKI, or ISI $_{M}$ between groups $B$ and C (Fig. 3).

Group $\mathrm{C}$ showed significant decreases in $\mathrm{IGI}_{30}$ and $\mathrm{DI}_{30}$ compared with group $\mathrm{B}$ and group $\mathrm{A}$ and a significant decrease in $\mathrm{DI}_{120}$ compared with group $\mathrm{B}$. Compared with group $\mathrm{A}$, group $\mathrm{B}$ did not show significant differences in $\mathrm{IGI}_{30}, \mathrm{DI}_{30}, \mathrm{IGI}_{120}$, or $\mathrm{DI}_{120}$. Compared with groups $\mathrm{A}$ and $\mathrm{B}$, group $\mathrm{D}$ showed significant decreases in $\mathrm{IGI}_{30}, \mathrm{DI}_{30}$, and $\mathrm{DI}_{120}$. Compared with group $\mathrm{C}$, group D showed significant decreases in $\mathrm{IGI}_{30}, \mathrm{DI} 30$, and $\mathrm{DI}_{120}$ (Fig. 3).

\section{Differences in insulin sensitivity and DI among groups divided by quartiles with respect to the levels of lipid components}

HOMA-IR was increased in participants who were in the 3rd and 4th quartiles for TG and LDL-c levels and 


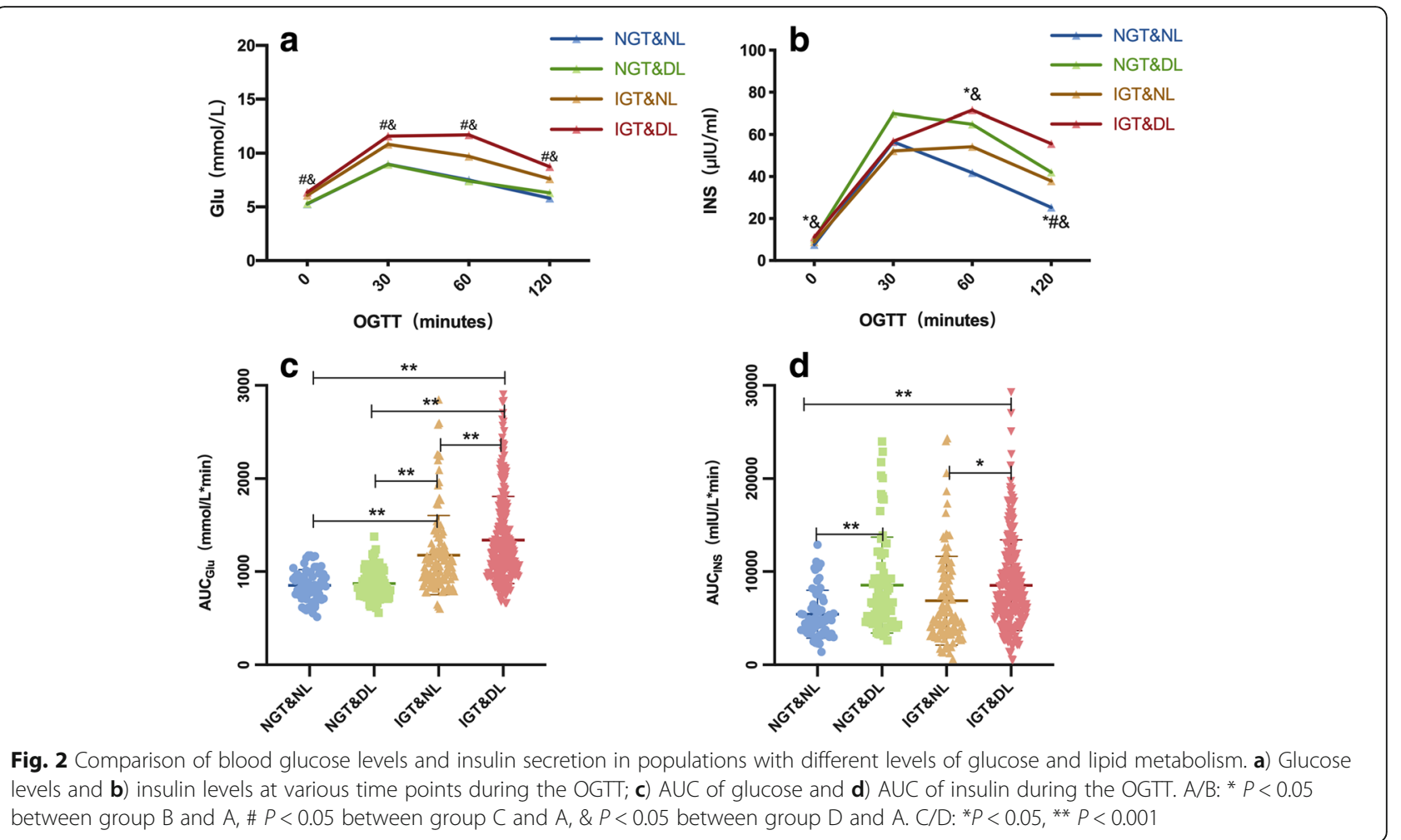

decreased in those who were in the 4th quartile for HDL-c levels compared with those who were in the 1st quartile for these individual lipid components. Similarly, ISI decreased according to the quartiles in which the participants fell with respect to TG and LDL-c levels but increased in individuals who were in the 3rd and 4th quartiles for HDL-c (Suppl. Figure 1). DI declined in participants who were in the higher quartiles for TG and LDL-c but did not change significantly as a function of quartile in the case of HDL-c. $\mathrm{DI}_{30}$ was decreased in participants who were in the 3rd and 4th quartiles for TG; however, participants in different quartiles for HDL-c and LDL-c did not show significant differences in $\mathrm{DI}_{30}$ (Suppl. Figure 2).

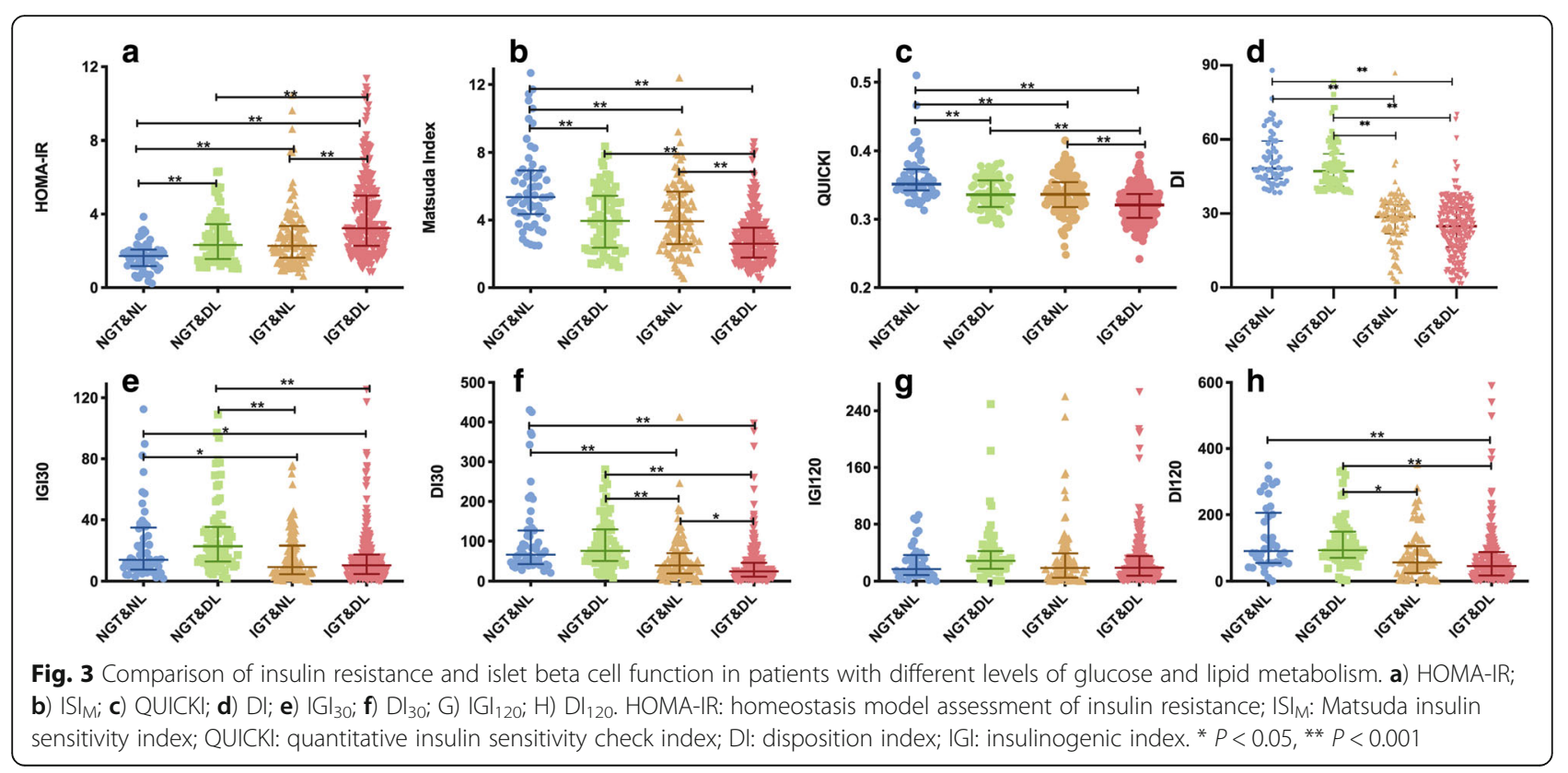


Relationship of serum lipid profiles and oxidative stress indicators to HOMA-IR and $\mathrm{DI}_{30}$

Spearman correlation analysis showed that TG, LDLc, and UA positively correlated with HOMA-IR and negatively correlated with $\mathrm{DI}_{30}$, while HDL-c and SOD levels negatively correlated with HOMA-IR. In addition, HDL-c levels positively correlated with $\mathrm{DI}_{30}$, while 8-OHdG levels negatively correlated with $\mathrm{DI}_{30}$ (Suppl. Table 2). The stratified multiple linear regression analysis showed that TG positively correlated with insulin resistance (LnHOMA-IR) in the NGT groups (groups A and B) and negatively correlated with beta cell function $\left(\mathrm{LnDI}_{30}\right)$ in the dyslipidemia groups (groups B and D). However, when adjustments were made for other confounding factors, HDL-c and LDL-c were no longer associated with insulin resistance or beta cell function (Tables 2 and 3). Then, partial correlation analysis was used to analyze the relationships between TG, HDL-c, LDL-c, and indicators of oxidative stress. The results indicated that TG negatively correlated with SOD level even after adjusting for age, gender, BMI, FPG, and UA ( $r=-$ $0.461, P<0.001)$. In addition, GR independently positively correlated with $\mathrm{LnDI}_{30}$, while $8-\mathrm{OHdG}$ was independently negatively correlated with $\mathrm{LnDI}_{30}$ in the individuals in group A (Table 3).

Table 2 Regression analysis using LnHOMA-IR as a dependent variable in groups with different glucose and lipid levels

\begin{tabular}{|c|c|c|c|c|c|c|c|c|}
\hline \multirow[b]{2}{*}{ Group A } & \multicolumn{3}{|c|}{ Simple linear regression } & \multicolumn{5}{|c|}{ Multiple linear regression } \\
\hline & B & Beta & $P$ & B & Beta & $P$ & VIF & \\
\hline Age & -0.019 & -0.443 & $<0.001$ & -0.018 & -0.415 & $<0.001$ & 1.361 & \\
\hline Gender & 0.364 & 0.31 & 0.014 & 0.145 & 0.124 & 0.198 & 1.373 & \\
\hline $\mathrm{BMI}\left(\mathrm{kg} / \mathrm{m}^{2}\right)$ & 0.065 & 0.362 & 0.004 & 0.045 & 0.254 & 0.005 & 1.161 & \\
\hline FPG $(\mathrm{mmol} / \mathrm{L})$ & 0.462 & 0.528 & $<0.001$ & 0.398 & 0.454 & $<0.001$ & 1.056 & \\
\hline $\mathrm{TG}(\mathrm{mmol} / \mathrm{L})$ & 0.546 & 0.321 & 0.011 & 0.412 & 0.242 & 0.007 & 1.136 & \\
\hline Adjusted R2 & & & & & & & & 0.599 \\
\hline Group B & B & Beta & $P$ & B & Beta & $P$ & VIF & \\
\hline Age & -0.008 & -0.201 & 0.076 & -0.01 & -0.241 & 0.018 & 1.125 & \\
\hline $\mathrm{BMI}\left(\mathrm{kg} / \mathrm{m}^{2}\right)$ & 0.066 & 0.407 & $<0.001$ & 0.055 & 0.331 & 0.004 & 1.408 & \\
\hline WC (cm) & 0.016 & 0.3 & 0.007 & 0.006 & 0.061 & 0.596 & 1.499 & \\
\hline $\mathrm{FPG}(\mathrm{mmol} / \mathrm{L})$ & 0.354 & 0.19 & 0.09 & 0.249 & 0.132 & 0.182 & 1.081 & \\
\hline TG $(\mathrm{mmol} / \mathrm{L})$ & 0.161 & 0.327 & 0.003 & 0.053 & 0.288 & 0.006 & 1.181 & \\
\hline LDL-C (mmol/L) & 0.114 & 0.194 & 0.083 & 0.062 & 0.08 & 0.451 & 1.266 & \\
\hline GR (U/L) & 0.031 & 0.2 & 0.073 & 0.016 & 0.096 & 0.343 & 1.13 & \\
\hline Adjusted R2 & & & & & & & & 0.307 \\
\hline Group C & B & Beta & $P$ & B & Beta & $P$ & VIF & \\
\hline Gender & 0.237 & 0.192 & 0.037 & 0.333 & 0.269 & 0.003 & 1.323 & \\
\hline $\mathrm{BMI}\left(\mathrm{kg} / \mathrm{m}^{2}\right)$ & 0.075 & 0.462 & $<0.001$ & 0.074 & 0.457 & $<0.001$ & 2.184 & \\
\hline WC (cm) & 0.012 & 0.18 & 0.053 & -0.007 & -0.107 & 0.344 & 2.098 & \\
\hline FPG (mmol/L) & 0.089 & 0.032 & 0.006 & 0.068 & 0.192 & 0.022 & 1.122 & \\
\hline TG $(\mathrm{mmol} / \mathrm{L})$ & 0.494 & 0.244 & 0.008 & 0.032 & 0.016 & 0.86 & 1.283 & \\
\hline $\mathrm{HDL}-\mathrm{c}(\mathrm{mmol} / \mathrm{L})$ & -0.627 & -0.225 & 0.015 & -0.526 & -0.185 & 0.062 & 1.585 & \\
\hline Adjusted R2 & & & & & & & & 0.302 \\
\hline Group D & B & Beta & $P$ & B & Beta & P & VIF & \\
\hline $\mathrm{BMI}\left(\mathrm{kg} / \mathrm{m}^{2}\right)$ & 0.059 & 0.396 & $<0.001$ & 0.048 & 0.317 & $<0.001$ & 1.394 & \\
\hline WC (cm) & 0.019 & 0.309 & $<0.001$ & 0.005 & 0.081 & 0.204 & 1.406 & \\
\hline FPG (mmol/L) & 0.105 & 0.39 & $<0.001$ & 0.114 & 0.394 & $<0.001$ & 1.092 & \\
\hline $\mathrm{TG}(\mathrm{mmol} / \mathrm{L})$ & 0.066 & 0.235 & $<0.001$ & 0.013 & 0.046 & 0.516 & 1.744 & \\
\hline $\mathrm{SOD}(\mathrm{U} / \mathrm{mL})$ & -0.004 & -0.184 & 0.005 & -0.001 & -0.042 & 0.545 & 1.704 & \\
\hline Adjusted R2 & & & & & & & & 0.33 \\
\hline
\end{tabular}


Table 3 Regression analysis using $\mathrm{LnDl}_{30}$ as a dependent variable in groups with different levels of glucose and lipid metabolism

\begin{tabular}{|c|c|c|c|c|c|c|c|c|}
\hline \multirow[b]{2}{*}{ Group A } & \multicolumn{3}{|c|}{ Simple linear regression } & \multicolumn{5}{|c|}{ Multiple linear regression } \\
\hline & $B$ & Beta & $P$ & $B$ & Beta & $P$ & VIF & \\
\hline Gender & 0.782 & 0.387 & 0.002 & 0.623 & 0.307 & 0.022 & 1.322 & \\
\hline Age & -0.023 & -0.295 & 0.024 & -0.01 & -0.13 & 0.322 & 1.331 & \\
\hline WC (cm) & -0.023 & -0.225 & 0.089 & -0.015 & -0.144 & 0.234 & 1.133 & \\
\hline LDL-C (mmol/L) & -0.575 & -0.275 & 0.035 & -0.178 & -0.085 & 0.506 & 1.261 & \\
\hline GR (U/L) & 0.094 & 0.312 & 0.016 & 0.079 & 0.262 & 0.027 & 1.045 & \\
\hline 8-OHdG (pg/mL) & -0.005 & -0.196 & 0.138 & -0.007 & -0.287 & 0.018 & 1.097 & \\
\hline Adjusted R2* & & & & & & & & 0.277 \\
\hline Group B & B & Beta & P & B & Beta & $P$ & VIF & \\
\hline Gender & 0.724 & 0.376 & 0.001 & 0.579 & 0.295 & 0.011 & 1.204 & \\
\hline Age & -0.014 & -0.203 & 0.085 & -0.014 & -0.202 & 0.058 & 1.041 & \\
\hline $\mathrm{TG}(\mathrm{mmol} / \mathrm{L})$ & -0.195 & -0.22 & 0.057 & -0.214 & -0.228 & 0.034 & 1.054 & \\
\hline $\mathrm{HDL}-\mathrm{c}(\mathrm{mmol} / \mathrm{L})$ & 1.102 & 0.266 & 0.021 & 0.916 & 0.218 & 0.054 & 1.068 & \\
\hline UA ( $\mu \mathrm{mol} / \mathrm{L})$ & -0.003 & -0.236 & 0.042 & -0.001 & -0.098 & 0.39 & 1.209 & \\
\hline Adjusted R2 & & & & & & & & 0.243 \\
\hline Group C & B & Beta & P & B & Beta & $P$ & VIF & \\
\hline Age & -0.026 & -0.236 & 0.017 & -0.021 & -0.188 & 0.013 & 1.019 & \\
\hline $\mathrm{TG}(\mathrm{mmol} / \mathrm{L})$ & -0.536 & -0.721 & $<0.001$ & -0.114 & -0.031 & 0.685 & 1.082 & \\
\hline FPG (mmol/L) & -0.697 & -0.179 & 0.071 & -0.555 & -0.645 & $<0.001$ & 1.084 & \\
\hline GR (U/L) & 0.057 & 0.169 & 0.099 & 0.032 & 0.093 & 0.224 & 1.053 & \\
\hline Adjusted R2 & & & & & & & & 0.488 \\
\hline Group D & B & Beta & $P$ & B & Beta & $P$ & VIF & \\
\hline WC (cm) & -0.025 & -0.184 & 0.006 & -0.009 & -0.068 & 0.142 & 1.088 & \\
\hline FPG (mmol/L) & -0.43 & -0.731 & $<0.001$ & -0.439 & -0.693 & $<0.001$ & 1.153 & \\
\hline TG (mmol/L) & -0.172 & -0.285 & $<0.001$ & -0.073 & -0.122 & 0.048 & 1.916 & \\
\hline $\mathrm{HDL}-\mathrm{C}(\mathrm{mmol} / \mathrm{L})$ & -0.65 & -0.165 & 0.012 & -0.157 & -0.04 & 0.391 & 1.107 & \\
\hline UA $(\mu \mathrm{mol} / \mathrm{L})$ & 0.002 & 0.113 & 0.088 & 0.001 & 0.07 & 0.138 & 1.114 & \\
\hline $\mathrm{SOD}(\mathrm{U} / \mathrm{mL})$ & 0.012 & 0.23 & $<0.001$ & -0.001 & -0.012 & 0.842 & 1.75 & \\
\hline Adjusted R2 & & & & & & & & 0.562 \\
\hline
\end{tabular}

BMI Body mass index, WC Waist circumference, FPG Fasting blood glucose, TG Triglyceride, HDL-c High-density lipoprotein, LDL-c Low-density lipoprotein, UA Uric acid, SOD Superoxide dismutase, GR Glutathione reductase, 8-OHdG 8-hydroxydeoxyguanosine

\section{Discussion}

In this study, cross-group analysis showed increased insulin resistance in patients with dyslipidemia and/or dysglycemia. Although insulin resistance was observed in people with dyslipidemia alone, islet beta cell function was sufficiently preserved to allow these individuals to maintain normal glucose homeostasis. Multiple linear regression analysis showed that TG positively correlated with insulin resistance in participants with NGT (groups A and B) and negatively correlated with beta cell function in individuals with dyslipidemia (groups B and D) independent of other confounding factors. These results suggest that in populations with different blood glucose and lipid levels, the factors that contribute to insulin resistance and beta cell dysfunction are different and that the mechanisms involved might also be different.

In this study, $72.1 \%$ of the presumed "healthy" population in the rural community actually displayed abnormal glucose tolerance $(22.8 \%$ had DM, and $49.3 \%$ had pre$\mathrm{DM})$, and $64.3 \%$ of the individuals tested had dyslipidemia. The prevalence of DM was higher than that reported by a previous study, which found that the prevalence of DM in the Chinese adult population was $11.6 \%$, while the prevalence of pre-DM $(50.1 \%)$ in that study was similar [31]. Additionally, the prevalence of dyslipidemia was substantially higher than those in previous studies that reported prevalence rates of 32.2 to 43.2\% in Chinese rural adults [32, 33]. However, another study showed that the prevalence of dyslipidemia is 60.7 
and $66.4 \%$ in rural and urban northeast Chinese adults aged over 40 years, respectively [34]. One important reason why that study and the present study showed a substantially higher prevalence of dyslipidemia might be due to the relatively older age of the participants. Hence, the prevalence of DM/pre-DM and dyslipidemia of the elderly in the Beijing rural community is high, while the rate of awareness is low. Therefore, more attention is needed to detect and manage DM/pre-DM and dyslipidemia in this population.

Patients with dyslipidemia exhibited severe insulin resistance compared with those without dyslipidemia, with or without dysglycemia. When both abnormalities were present, the degree of insulin resistance was further aggravated. These results are partially in accordance with those reported in a previous study in which elevated HOMA-IR was found in people with dyslipidemia alone [35]. Multiple linear regression analysis after population stratification showed that TG positively correlated with insulin resistance only in individuals with NGT (groups A and B). That is, in the absence of dysglycemia, an elevated TG level might be an important independent risk factor for insulin resistance. A previous study showed that both fenofibrate alone and the combination of omega- 3 fatty acids and fenofibrate not only decreased triglycerides but also improved insulin sensitivity in patients with hypertriglyceridemia [36], thus showing a potential benefit of improving insulin resistance by combating hypertriglyceridemia. Therefore, the monitoring and control of hypertriglyceridemia in patients with dyslipidemia should be strengthened to improve insulin resistance.

Multiple linear regression analysis showed that TG was independently and negatively correlated with $\mathrm{LnDI}_{30}$ in patients with dyslipidemia (groups B and D), suggesting that an increased TG level is an independent risk factor for beta cell dysfunction in patients with dyslipidemia. Compared with the patients in group B, those in group D had higher TG levels, more severe insulin resistance, and significantly impaired early- and late-phase islet beta cell function. That is, as TG levels increase, insulin resistance and insulin secretion deficiency might worsen, and dysglycemia might occur. A previous T2DM cohort study found that log (TG/HDL-c) predicted the rate of decline in islet beta cell function [37]. In another study, Andrea Natali et al. reported that high TG and low HDL-c levels might be risk factors contributing to reduced insulin secretion in a nondiabetic cohort [17], a finding that is partially consistent with the results of the present study. However, in this study, HDL-c levels did not correlate with insulin resistance or beta cell function after adjustment for confounding factors. These discrepant results might be the consequences of differences in grouping and in adjustments for confounding factors in the multiple regression analysis.
As shown above, TG levels positively correlated with insulin resistance in individuals with NGT and negatively correlated with beta cell function in patients with dyslipidemia. That is, in patients with NGT associated with dyslipidemia, elevated TG not only aggravated insulin resistance but also accelerated islet beta cell dysfunction. Therefore, for patients with dyslipidemia, even if the blood glucose is normal, the management of hypertriglyceridemia should be strengthened. In addition to lifestyle modifications and the use of drugs such as fibrates, niacin, and n-3 fatty acids to combat hypertriglyceridemia, as recommended by Endocrine Society Clinical Practice Guidelines [38], certain nutraceuticals, such as fish oil, grape seed, mulberry, soy milk, and green, oolong, black, and pu-erh teas, might also be effective in reducing TG levels [39]. Furthermore, two randomized controlled trial studies conducted in India showed that saroglitazar, a dual peroxisome proliferatoractivated receptor (PPAR) $\alpha /$ agonist, lowers postprandial TG levels [40] and improves insulin sensitivity assessed using hyperinsulinemic-euglycemic clamp in patients with T2DM and hypertriglyceridemia [41]. These findings demonstrate the potential benefit and significant value of treatment of hypertriglyceridemia in improving insulin resistance.

As the primary antioxidant enzyme in the body, SOD removes ROS and reduces oxidative damage to cells and tissues. In this study, patients with dysglycemia plus dyslipidemia (group D) presented with significantly decreased SOD levels. In addition, SOD levels negatively correlated with insulin resistance, although the association disappeared after adjustment for confounding factors, including TG. However, TG was negatively correlated with SOD levels after adjustment for confounding factors, indicating that SOD might be involved in the connection between TG levels and insulin resistance. These results suggest that dyslipidemia might decrease SOD activity in patients with dysglycemia, aggravating oxidative stress damage and thereby impairing beta cell function. Another possibility is that the decreased SOD activity might induce hypertriglyceridemia, thereby aggravating insulin resistance and beta cell dysfunction. Some studies have demonstrated decreased SOD levels in patients with diabetes [42, 43], while other studies have reported increased or unchanged SOD levels in diabetic patients [44, 45]. A cross-sectional study showed that serum SOD level negatively correlates with BMI, TG, BG, and carotid artery intima-media thickness [46], in accordance with the present study. Perriotte-Olson et al. found that mice fed a high-fat diet and treated with nanoformulated SOD (NanoSOD) showed significant decreases in plasma and liver TG levels [47], and improved glucose and lipid metabolism [48]. The evidence above indicates that SOD plays an 
important role in glucose and lipid metabolism, and the mechanism of its effect requires further study.

Reduced glutathione (GSH) and GR are also important components of the antioxidant system in the body. 8OHdG is a product of DNA damage caused by ROS [49] and can be used as a sensitive marker of DNA oxidative damage [50, 51]. Previous studies have reported that serum GSH levels and GR activity are decreased in patients with T2DM [45], and that the levels of 8-OHdG in blood and urine are significantly higher in diabetic or prediabetic populations [52-54]. In the present study, stratified regression analysis revealed that GR activity positively correlated with islet beta cell function and that 8-OHdG negatively correlated with beta cell function in individuals with normal blood glucose and lipid levels. These results suggest that GR plays an important role in maintaining normal islet beta cell function, whereas oxidative stress might impair beta cell function in the early stage, when hyperglycemia has not yet occurred. Therefore, paying attention to the role of oxidative stress prior to the occurrence of DM and dyslipidemia is promising and helpful. Hence, the relationship between oxidative stress and glucose-lipid metabolism is complex, and further investigation is needed to confirm the causality.

\section{Strengths and limitation}

The strengths of this study are as follows. The population was grouped according to the patients' levels of glucose and lipid metabolism and was also stratified in the regression analysis to avoid unrealistic analytical results based on an unstratified population. In addition to the results of the glucose tolerance test and the lipid profiles, oxidative stress indicators were included in the analysis, allowing us to rule out the impact of relevant confounding factors on the results. This study also has disadvantages and limitations. It is a cross-sectional study, and the conclusions obtained cannot be used to infer causality and must be further confirmed in follow-up cohort studies. In addition, no differences in GR activity or 8-OHdG levels among the four groups were found, possibly due to the relatively small sample size after grouping.

\section{Conclusions}

TG levels positively correlated with insulin resistance in individuals with NGT and negatively correlated with beta cell function in people with dyslipidemia. Therefore, it is necessary to strengthen the control of hypertriglyceridemia in individuals with dyslipidemia, even when the glucose tolerance test is normal. In addition, oxidative stress might affect islet cell function at an early stage prior to the occurrence of abnormal glucose and lipid metabolism, which requires further investigation to gain a better understanding of the mechanisms that lead to DM as well as to arrest DM at an early stage.

\section{Supplementary information}

Supplementary information accompanies this paper at https://doi.org/10. 1186/s12944-020-01303-w.

Additional file 1: Table S1. Comparisons of blood glucose levels and insulin secretion at various time points during the OGTT for the general population and for populations with different levels of glucose and lipid metabolism. Table S2. Spearman correlation analysis of blood glucose, serum lipid levels, and oxidative stress indicators with HOMA-IR and $\mathrm{Dl}_{30}$ in the general population. Figure S1. Comparison of HOMA-IR and ISI $M$ in patients according to quartiles of lipid profiles. ${ }^{*} P<0.05$, ${ }^{*} P<0.001$.

\section{Abbreviations}

NGT: Normal glucose tolerance; IFG: Impaired fasting glucose; IGT: Impaired glucose tolerance; Pre-DM: Prediabetes mellitus; T2DM: Type 2 diabetes mellitus; CVD: Cardiovascular disease; WC: Waist circumference; SBP: Systolic blood pressure; DBP: Diastolic blood pressure; BMI: Body mass index; OGTT: Oral glucose tolerance test; FPG: Fasting plasma glucose; HbA1c: Glycosylated hemoglobin; TG: Triglyceride; TC: Total cholesterol; HDLc: High-density lipoprotein cholesterol; LDL-c: Low-density lipoprotein cholesterol; UA: Uric acid; ROS: Reactive oxygen species; SOD: Superoxide dismutase; GR: Glutathione reductase; GSH: Reduced glutathione; 8-OHdG: 8hydroxydeoxyguanosine; HOMA-IR: Homeostasis model assessment of insulin resistance; ISI $I_{M}$ : Matsuda insulin sensitivity index; QUICKI: Quantitative insulin sensitivity check index; IGI: Insulinogenic index; DI: Disposition index; Ln: Natural log transformation

\section{Acknowledgments}

We thank all of the authors, the individuals who participated in the study, and American Journal Experts for their language support.

\section{Authors' contributions}

$M M L$ analyzed the data and made a major contribution to the writing of the manuscript. YJ, HSL, LW, and SQ collected the data. ZHB, PF, XLL, and LYX helped revise the manuscript. LHB, LPP, and MCX helped interpret the data. All authors read and approved the final manuscript.

\section{Funding}

This work was supported by the National Natural Science Foundation of China [grant number 81270878] and the CAMS Innovation Fund for Medical Sciences (CIFMS, CIFMS2016-I2M-4-001).

\section{Availability of data and materials}

The datasets used and/or analyzed in the current study are available from the corresponding author upon reasonable request.

\section{Ethics approval and consent to participate}

The study protocol was approved by the Ethics Committee of Peking Union Medical College Hospital. The participants voluntarily signed informed consent forms.

\section{Consent for publication \\ Not applicable.}

\section{Competing interests}

The authors have no competing interests to declare.

\section{Author details}

${ }^{1}$ Department of Endocrinology, Key Laboratory of Endocrinology, Ministry of Health, Peking Union Medical College Hospital, Beijing 100730, China.

${ }^{2}$ Department of Basic Physiology, The Health School affiliated with Capital Medical University, Beijing, China. ${ }^{3}$ Department of Nutrition, Peking Union Medical College Hospital, Beijing, China. ${ }^{4}$ State Key Laboratory of Bioactive Substance and Function of Natural Medicines, Institute of Materia Medica, Chinese Academy of Medical Sciences and Peking Union Medical College, Beijing 100050, China. ${ }^{5}$ Diabetes Research Center of the Chinese Academy of Medical Sciences, Beijing 100050, China. 
Received: 7 April 2019 Accepted: 28 May 2020

Published online: 02 June 2020

\section{References}

1. Verges B. Pathophysiology of diabetic dyslipidaemia: where are we? Diabetologia. 2015;58(5):886-99.

2. Haffner SM. Management of dyslipidemia in adults with diabetes. Diabetes Care. 2003;26(Suppl 1):S83-6.

3. American Diabetes Association. 9. Cardiovascular Disease and Risk Management: Standards of Medical Care in Diabetes-2018. Diabetes Care. 2018:41(Suppl 1):S86-s104

4. Soran H, Schofield JD, Adam S, Durrington PN. Diabetic dyslipidaemia. Cur Opin Lipidol. 2016:27(4):313-22.

5. Abdul-Ghani MA, Tripathy D, DeFronzo RA. Contributions of beta-cell dysfunction and insulin resistance to the pathogenesis of impaired glucose tolerance and impaired fasting glucose. Diabetes Care. 2006;29(5):1130-9.

6. Staimez LR, Weber MB, Ranjani H, Ali MK, Echouffo-Tcheugui JB, Phillips LS, Mohan V, Narayan KM. Evidence of reduced beta-cell function in Asian Indians with mild dysglycemia. Diabetes Care. 2013;36(9):2772-8.

7. Zhou M, Zhu L, Cui X, Feng L, Zhao X, He S, Ping F, Li W, Li Y. The triglyceride to high-density lipoprotein cholesterol (TG/HDL-C) ratio as a predictor of insulin resistance but not of beta cell function in a Chinese population with different glucose tolerance status. Lipids Health Dis. 2016; $15 \cdot 104$

8. Chiang JK, Lai NS, Chang JK, Koo M. Predicting insulin resistance using the triglyceride-to-high-density lipoprotein cholesterol ratio in Taiwanese adults. Cardiovasc Diabetol. 2011;10:93.

9. Salazar MR, Carbajal HA, Espeche WG, Leiva Sisnieguez CE, Balbin E, Dulbecco CA, Aizpurua M, Marillet AG, Reaven GM. Relation among the plasma triglyceride/high-density lipoprotein cholesterol concentration ratio, insulin resistance, and associated cardio-metabolic risk factors in men and women. Am J Cardiol. 2012;109(12):1749-53.

10. Unger RH. Lipotoxicity in the pathogenesis of obesity-dependent NIDDM. Genetic and clinical implications. Diabetes. 1995;44(8):863-70.

11. Prentki M, Matschinsky FM, Madiraju SR. Metabolic signaling in fuel-induced insulin secretion. Cell Metab. 2013;18(2):162-85.

12. Poitout V, Robertson RP. Glucolipotoxicity: fuel excess and beta-cell dysfunction. Endocr Rev. 2008;29(3):351-66.

13. Poitout V, Amyot J, Semache M, Zarrouki B, Hagman D, Fontes G. Glucolipotoxicity of the pancreatic beta cell. Biochim Biophys Acta. 2010; 1801(3):289-98.

14. Giacca A, Xiao C, Oprescu Al, Carpentier AC, Lewis GF. Lipid-induced pancreatic beta-cell dysfunction: focus on in vivo studies. Am J Physiol Endocrinol Metab. 2011;300(2):E255-62.

15. El-Assaad W, Joly E, Barbeau A, Sladek R, Buteau J, Maestre I, Pepin E, Zhao S, Iglesias J, Roche E, et al. Glucolipotoxicity alters lipid partitioning and causes mitochondrial dysfunction, cholesterol, and ceramide deposition and reactive oxygen species production in INS832/13 ss-cells. Endocrinology. 2010;151(7):3061-73

16. Zheng S, Zhou H, Han T, Li Y, Zhang Y, Liu W, Hu Y. Clinical characteristics and beta cell function in Chinese patients with newly diagnosed type 2 diabetes mellitus with different levels of serum triglyceride. BMC Endocr Disord. 2015;15:21

17. Natali A, Baldi S, Bonnet F, Petrie J, Trifiro S, Trico D, Mari A. Plasma HDLcholesterol and triglycerides, but not LDL-cholesterol, are associated with insulin secretion in non-diabetic subjects. Metabolism. 2017:69:33-42.

18. Sakuraba H, Mizukami H, Yagihashi N, Wada R, Hanyu C, Yagihashi S. Reduced beta-cell mass and expression of oxidative stress-related DNA damage in the islet of Japanese type II diabetic patients. Diabetologia. 2002; 45(1):85-96.

19. Karunakaran U, Park KG. A systematic review of oxidative stress and safety of antioxidants in diabetes: focus on islets and their defense. Diabetes Metab J. 2013;37(2):106-12

20. Robertson R, Zhou H, Zhang T, Harmon JS. Chronic oxidative stress as a mechanism for glucose toxicity of the beta cell in type 2 diabetes. Cell Biochem Biophys. 2007;48(2-3):139-46.

21. Kajimoto $Y$, Kaneto $H$. Role of oxidative stress in pancreatic beta-cell dysfunction. Ann N Y Acad Sci. 2004;1011:168-76.

22. Keane KN, Cruzat VF, Carlessi R, de Bittencourt PI Jr, Newsholme P. Molecular Events Linking Oxidative Stress and Inflammation to Insulin
Resistance and beta-Cell Dysfunction. Oxid Med Cell Longev. 2015;2015: 181643. https://doi.org/10.1155/2015/181643.

23. Wang J, Wang H. Oxidative Stress in Pancreatic Beta Cell Regeneration. Oxid Med Cell Longev. 2017:2017:1930261. https://doi.org/10.1155/2017/1930261.

24. WHO Expert Consultation. Appropriate body-mass index for Asian populations and its implications for policy and intervention strategies. Lancet. 2004;363(9403):157-63.

25. Matthews DR, Hosker JP, Rudenski AS, Naylor BA, Treacher DF, Turner RC. Homeostasis model assessment: insulin resistance and beta-cell function from fasting plasma glucose and insulin concentrations in man. Diabetologia. 1985;28(7):412-9.

26. Matsuda M, DeFronzo RA. Insulin sensitivity indices obtained from oral glucose tolerance testing: comparison with the euglycemic insulin clamp. Diabetes Care. 1999;22(9):1462-70.

27. Katz A, Nambi SS, Mather K, Baron AD, Follmann DA, Sullivan G, Quon MJ. Quantitative insulin sensitivity check index: a simple, accurate method for assessing insulin sensitivity in humans. J Clin Endocrinol Metab. 2000;85(7): 2402-10.

28. Haffner SM, Miettinen H, Gaskill SP, Stern MP. Decreased insulin secretion and increased insulin resistance are independently related to the 7-year risk of NIDDM in Mexican-Americans. Diabetes. 1995;44(12):1386-91.

29. Matsuda M. Measuring and estimating insulin resistance in clinical and research settings. Nutr Metab Cardiovasc Dis. 2010;20(2):79-86.

30. Abdul-Ghani MA, Williams K, DeFronzo RA, Stern M. What is the best predictor of future type 2 diabetes? Diabetes Care. 2007;30(6):1544-8. https://doi.org/10.2337/dc06-1331.

31. Xu Y, Wang L, He J, Bi Y, Li M, Wang T, Wang L, Jiang Y, Dai M, Lu J, et al. Prevalence and control of diabetes in Chinese adults. Jama. 2013;310(9): 948-59.

32. Opoku S, Gan Y, Fu W, Chen D, Addo-Yobo E, Trofimovitch D, Yue W, Yan F, Wang Z, Lu Z. Prevalence and risk factors for dyslipidemia among adults in rural and urban China: findings from the China National Stroke Screening and prevention project (CNSSPP). BMC Public Health. 2019;19(1):1500.

33. Liu X, Yu S, Mao Z, Li Y, Zhang H, Yang K, Zhang H, Liu R, Qian X, Li L, et al. Dyslipidemia prevalence, awareness, treatment, control, and risk factors in Chinese rural population: the Henan rural cohort study. Lipids Health Dis. 2018;17(1):119.

34. Zhang FL, Xing YQ, Wu YH, Liu HY, Luo Y, Sun MS, Guo ZN, Yang Y. The prevalence, awareness, treatment, and control of dyslipidemia in Northeast China: a population-based cross-sectional survey. Lipids Health Dis. 2017; 16(1):61.

35. Zheng S, Xu H, Zhou H, Ren X, Han T, Chen Y, Qiu H, Wu P, Zheng J, Wang $L$, et al. Associations of lipid profiles with insulin resistance and beta cell function in adults with normal glucose tolerance and different categories of impaired glucose regulation. PLoS One. 2017;12(2):e0172221. https://doi.org/ 10.1371/journal.pone.0172221.

36. Koh KK, Oh PC, Sakuma I, Lee Y, Han SH, Shin EK. Vascular and metabolic effects of omega-3 fatty acids combined with fenofibrate in patients with hypertriglyceridemia. Int J Cardiol. 2016;221:342-6.

37. Zhou M, Li Z, Min R, Dong Y, Sun Q, Li Y. Log (TG)/HDL-C ratio as a predictor of decreased islet beta cell function in patients with type 2 diabetes: 6-year cohort study. J Diabetes. 2015;7(5):689-98.

38. Berglund L, Brunzell JD, Goldberg AC, Goldberg IJ, Sacks F, Murad MH, Stalenhoef AF. And endocrine s. evaluation and treatment of hypertriglyceridemia: an Endocrine Society clinical practice guideline. J Clin Endocrinol Metab. 2012;97(9):2969-89.

39. Scicchitano P, Cameli M, Maiello M, Modesti PA, Muiesan ML, Novo S, Palmiero P, Saba PS, Pedrinelli R, Ciccone MM. Nutraceuticals and dyslipidaemia: beyond the common therapeutics. J Funct Foods. 2014;6:11-32.

40. Rastogi A, Dunbar RL, Thacker HP, Bhatt J, Parmar K, Parmar DV. Abrogation of postprandial triglyceridemia with dual PPAR alpha/gamma agonist in type 2 diabetes mellitus: a randomized, placebo-controlled study. Acta Diabetol. 2020. https://doi.org/10.1007/s00592-020-01487-8.

41. Jain N, Bhansali S, Kurpad AV, Hawkins M, Sharma A, Kaur S, Rastogi A, Bhansali A. Effect of a dual PPAR alpha/gamma agonist on insulin sensitivity in patients of type 2 diabetes with hypertriglyceridemia- randomized double-blind placebo-controlled trial. Sci Rep. 2019;9(1):19017. https://doi. org/10.1038/s41598-019-55466-3.

42. Colak E, Majkic-Singh N, Stankovic S, Sreckovic-Dimitrijevic V, Djordjevic PB, Lalic K, Lalic N. Parameters of antioxidative defense in type 2 diabetic patients with cardiovascular complications. Ann Med. 2005;37(8):613-20. 
43. Wong FN, Chua KH, Tan J, Wong CM, Kuppusamy UR. Glycaemic control in type 2 diabetic patients with chronic kidney disease: the impacts on enzymatic antioxidants and soluble RAGE. PeerJ. 2018;6:e4421. https://doi. org/10.7717/peerj.4421.

44. Picu A, Petcu L, Stefan S, Mitu M, Lixandru D, lonescu-Tirgoviste C, Pircalabioru GG, Ciulu-Costinescu F, Bubulica MV, Chifiriuc MC. Markers of Oxidative Stress and Antioxidant Defense in Romanian Patients with Type 2 Diabetes Mellitus and Obesity. Molecules. 2017;22(5). https://doi.org/10. 3390/molecules22050714.

45. Aouacheri O, Saka S, Krim M, Messaadia A, Maidi I. The investigation of the oxidative stress-related parameters in type 2 diabetes mellitus. Can J Diabetes. 2015;39(1):44-9.

46. Isogawa A, Yamakado M, Yano M, Shiba T. Serum superoxide dismutase activity correlates with the components of metabolic syndrome or carotid artery intima-media thickness. Diabetes Res Clin Pract. 2009:86(3):213-8.

47. Perriotte-Olson C, Adi N, Manickam DS, Westwood RA, Desouza CV, Natarajan G, Crook A, Kabanov AV, Saraswathi V. Nanoformulated copper/ zinc superoxide dismutase reduces adipose inflammation in obesity. Obesity (Silver Spring). 2016;24(1):148-56.

48. Natarajan G, Perriotte-Olson C, Bhinderwala F, Powers R, Desouza CV, Talmon GA, Yuhang J, Zimmerman MC, Kabanov AV, Saraswathi V. Nanoformulated copper/zinc superoxide dismutase exerts differential effects on glucose vs lipid homeostasis depending on the diet composition possibly via altered AMPK signaling. Transl Res. 2017;188:10-26.

49. Shigenaga MK, Gimeno CJ, Ames BN. Urinary 8-hydroxy-2'-deoxyguanosine as a biological marker of in vivo oxidative DNA damage. Proc Natl Acad Sci U S A. 1989;86(24):9697-701.

50. Valavanidis A, Vlachogianni T, Fiotakis C. 8-hydroxy-2' -deoxyguanosine (8OHdG): a critical biomarker of oxidative stress and carcinogenesis. J Environ Sci Health C Environ Carcinog Ecotoxicol Rev. 2009;27(2):120-39.

51. Wu LL, Chiou CC, Chang PY, Wu JT. Urinary 8-OHdG: a marker of oxidative stress to DNA and a risk factor for cancer, atherosclerosis and diabetics. Clin Chim Acta. 2004;339(1-2):1-9.

52. Hinokio Y, Suzuki S, Hirai M, Chiba M, Hirai A, Toyota T. Oxidative DNA damage in diabetes mellitus: its association with diabetic complications. Diabetologia. 1999;42(8):995-8.

53. Al-Aubaidy HA, Jelinek HF. 8-Hydroxy-2-deoxy-guanosine identifies oxidative DNA damage in a rural prediabetes cohort. Redox Rep. 2010;15(4):155-60.

54. Al-Aubaidy HA, Jelinek HF. Oxidative DNA damage and obesity in type 2 diabetes mellitus. Eur J Endocrinol. 2011;164(6):899-904.

\section{Publisher's Note}

Springer Nature remains neutral with regard to jurisdictional claims in published maps and institutional affiliations.

Ready to submit your research? Choose BMC and benefit from:

- fast, convenient online submission

- thorough peer review by experienced researchers in your field

- rapid publication on acceptance

- support for research data, including large and complex data types

- gold Open Access which fosters wider collaboration and increased citations

- maximum visibility for your research: over $100 \mathrm{M}$ website views per year

At $\mathrm{BMC}$, research is always in progress.

Learn more biomedcentral.com/submissions 